\title{
Variation of the Myelin Oligodendrocyte Glycoprotein gene is not primarily associated with multiple sclerosis in the Sardinian population
}

Maria Giovanna Marrosu루, Raffaele Murru ${ }^{1}$, Gianna Costa ${ }^{1}$, Maria Cristina Melis ${ }^{1}$, Marcella Rolesu ${ }^{1}$, Lucia Schirru ${ }^{1}$, Elisabetta Solla ${ }^{1}$, Stefania Cuccu ${ }^{1}$, Maria Antonietta Secci ${ }^{1}$, Michael B Whalen ${ }^{3}$, Eleonora Cocco ${ }^{1}$, Maura Pugliatti ${ }^{2}$, Stefano Sotgiu ${ }^{2}$, Giulio Rosati ${ }^{2}$ and Francesco Cucca*3

Address: ${ }^{1}$ Centro Sclerosi Multipla, Dipartimento di Scienze Neurologiche e Cardiovascolari, University of Cagliari, Italy, ${ }^{2}$ Istituto di Neurologia Clinica, Facoltà di Medicina e Chirurgia, University of Sassari, Italy and 32Dipartimento di Scienze Biomediche, University of Sassari, Italy

Email: Maria Giovanna Marrosu - gmarrosu@unica.it; Raffaele Murru - rmurru@unica.it; Gianna Costa - csm@unica.it; Maria Cristina Melis - csm@unica.it; Marcella Rolesu - csm@unica.it; Lucia Schirru - csm@unica.it; Elisabetta Solla - csm@unica.it; Stefania Cuccu - csm@unica.it; Maria Antonietta Secci - csm@unica.it; Michael B Whalen - whalenmb@hotmail.com; Eleonora Cocco - ecocco@unica.it; Maura Pugliatti - maurap@uniss.it; Stefano Sotgiu - stefanos@uniss.it; Giulio Rosati - webmed@uniss.it; Francesco Cucca* - fcucca@uniss.it

${ }^{*}$ Corresponding author

Published: 17 May 2007

BMC Genetics 2007, 8:25 doi:10.1 186/147|-2156-8-25
Received: 25 October 2006

Accepted: 17 May 2007

This article is available from: http://www.biomedcentral.com/I47I-2/56/8/25

(c) 2007 Marrosu et al; licensee BioMed Central Ltd.

This is an Open Access article distributed under the terms of the Creative Commons Attribution License (http://creativecommons.org/licenses/by/2.0), which permits unrestricted use, distribution, and reproduction in any medium, provided the original work is properly cited.

\begin{abstract}
Background: Multiple sclerosis (MS) is consistently associated with particular HLA-DRBI-DQBI haplotypes. However, existing evidence suggests that variation at these loci does not entirely explain association of the HLA region with the disease. The MOG locus is a prime positional and functional candidate for such additional predisposing effects but the analysis is complicated by the strong, albeit labyrinthine pattern of linkage disequilibrium in the region. Here we have assessed the association of MOG variation with MS in the Sardinian population to see if it represents an independent contributor to MS predisposition.
\end{abstract}

Results: After re-sequencing the MOG gene in 2 I healthy parents of MS patients we detected I34 variants, 33 of which were novel. A set of 40 informative SNPs was then selected and assessed for disease association together with I intragenic microsatellite in an initial data set of 239 MS families. This microsatellite and II SNPs were found to be positively associated with MS, using the transmission disequilibrium test, and were followed up in an additional 158 families (total families analysed $=397$ ). While in these 397 families, 8 markers showed significant association with MS, through conditional tests we determined that these MOG variants were not associated with MS independently of the main $D R B I-D Q B /$ disease associations.

Conclusion: These results indicate that variation within the MOG gene is not an important independent determinant of MS-inherited risk in the Sardinian population. 


\section{Background}

Multiple sclerosis (MS) is a serious chronic inflammatory and demyelinizating disorder of the central nervous system which results from an autoimmune attack on components of the oligodendrocyte cell [1]. The disease is more common in European and European-derived populations. Within Europe it shows a north-south gradient, with the notable exception of the Mediterranean island of Sardinia, which has one of the highest prevalences worldwide [2]. The disease risk for a monozygotic twin of an affected patient is about $30 \%$, showing a quick fall-off rate with decreased genetic relatedness to affected individuals. These data, and the increasing incidence of disease reported in some populations over the last few decades $[3,4]$, suggest that the chance of this inflammatory process occurring depends on the complex interplay between a polygenic trait and unknown environmental factors influencing the penetrance of susceptibility genes $[5,6]$. MS has been found to be consistently associated with specific HLA class II variants and notably with the HLADRB1*1501-DQB1*0602 haplotype, which represents the main risk factor for disease occurrence in different ethnic backgrounds [7-11]. The relative contribution of variation at the DRB1 and DQB1 loci to disease predisposition is still not completely clear although some studies based on cross-comparing rare HLA DRB1-DQB1 haplotype splits have indicated that the main contribution comes from variation at the DRB1 locus [11]. Analysis of large data sets from Finland and Canada have also suggested that in those populations, any important additional modifiers of MS susceptibility were likely to be contained in the regions close to DRB1 [12]. In Sardinia, the HLA-DRB1*1501-DQB1*0602 haplotype is rare but is still significantly positively associated with MS together with an additional 4 haplotypes including DRB1*1303DQB1*0301， DRB1*0405-DQB1*0301， DRB1*0301DQB $1 * 0201$ and DRB $1 * 0405-\mathrm{DQB} 1 * 0302$ [13]. Some of these haplotypes, such as DRB1*0301-DQB1*0201 are also associated with MS in some non-Sardinian populations $[11,14,15]$ but not in others $[8,9,16-20]$. The presence of HLA non-DRB1-DQB1 predisposing effects related to a different distribution of extended HLA-DRB1*0301DQB1*0201 haplotypes in different populations can explain these findings. Indeed, some studies have suggested that within the HLA region there are further independent predisposing effects determined by as yet unidentified non-DRB1-DQB1 variants [13,21-24]. However, strong linkage disequilibrium (LD) between the variants contained in the HLA region makes it difficult to detect which polymorphisms, outside the exon 2 sequences of the DR/DQ loci but within the HLA region, further influence disease risk. Within the HLA region, the MOG gene is a prime candidate for additional MS associations. This gene is located, $2.9 \mathrm{Mb}$ telomeric of the DRB1 locus, in a chromosome interval which has shown some evidence of association with MS independent of DRB1DQB1 [13]. Furthermore, the rodent ortholog of this gene encodes for an autoantigen which triggers autoimmune responses in experimental models of disease $[25,26]$. Moreover, in MS patients both T-cell and antibody responses against this protein have been detected $[27,28]$ and an aetiologic role of anti-MOG antibodies has been suggested in acute lesions of MS patients [29], although this role is controversial $[30,31]$. These findings could be consistent with a model in which specific polymorphisms in the MOG gene could determine amino acid variation or differences in the level of expression of this protein in the central nervous system and affect immune responses against it, thus acting as primary aetiologic determinants of disease pathogenesis.

A few studies have tested the association between MOG polymorphisms and disease, with conflicting results. Some of these studies indicated a potential role of MOG $[32,33]$ while others failed to find any evidence of primary association with MS $[34,35,12]$. However, none of these studies analysed the MOG gene comprehensively, nor assessed the association of genetic variation of this gene in the context of extended DRB1-DQB1-MOG haplotypes.

The aim of this study was to establish the SNP content of the MOG gene in the Sardinian population and use this information together with appropriate conditional association tests to assess the individual contribution of the MOG gene to MS inherited risk to determine if it is an important independent risk locus.

\section{Results and discussion}

In order to assess the association of MOG variation with MS we first established polymorphism content of the MOG gene in the Sardinian population by resequencing the gene in 21 healthy parents of MS patients. The primers used are listed in Table 1, and technical details are reported in the Methods section. We detected 134 SNPs, 101 of which had already been reported [36] and 33 were novel. A set of 40 informative SNPs was then selected to be tested for disease association (see Methods). These were initially genotyped in a data set of 239 MS families. To identify the haplotype-tagging patterns, we computed the intermarker $D^{\prime}$ and $r 2$ values of these 40 informative SNPs, computed for 478 parents of the MS patients, shown in Figure 1. The physical positions, with base 1165 corresponding to the translation start site of $M O G$, and other relevant information are indicated in Table 2. $D^{\prime}$ values indicate that these SNPs are part of the same linkage disequilibrium block (average 0.97 between contiguous marker pairs) that, as we have previously shown, encompasses HLA class I and III sub-regions and also includes the HLA class II DR and DQ loci $[37,13]$. As expected, considering selected SNPs were chosen in order to avoid 
Table I:

\begin{tabular}{cccc}
\hline Primers & Forward 5'-3' & Reverse $5^{\prime}-3^{\prime}$ & $\mathrm{TM}$ \\
& & & \\
\hline 1 & atgcaacagggagaaagagc & gaccagcattggtagcaggt & $57^{\circ} \mathrm{C}$ \\
2 & tggacagcacggctctaaat & tggacagcacggctctaaat & $58^{\circ} \mathrm{C}$ \\
3 & ggtctggtgatgacagttgtg & ggaagggaggcatgtcagta & $60^{\circ} \mathrm{C}$ \\
4 & tgtattttagtacagacggggtttc & tggtgcctgattatgcagag & $60^{\circ} \mathrm{C}$ \\
5 & gcttagcagtgcctgtccat & gccaaattgctgcctattct & $58^{\circ} \mathrm{C}$ \\
6 & agggtggaagatctcagaag & caaagcgctgggattatg & $57^{\circ} \mathrm{C}$ \\
7 & gctgaggcaggagaatcact & ttggccacccaacagttaat & $59^{\circ} \mathrm{C}$ \\
8 & aaataaaaaggaagaagaagaaga & ccaccaacagttaataccta & $57^{\circ} \mathrm{C}$ \\
9 & ggcagcaatggaattgaaag & cccacagtgctgggattac & $58^{\circ} \mathrm{C}$ \\
10 & ccaggggtttgcagttacag & gcttattcactaggaccaagcac & $57^{\circ} \mathrm{C}$ \\
11 & ttgcagtgagccaaaatcc & tcaccatcatgcaaaacat & $63^{\circ} \mathrm{C}$ \\
12 & tgacctcaggtgatccactc & ggtgaaactgagggagtttg & $62^{\circ} \mathrm{C}$ \\
13 & tgagaccctctccagtttgc & agacgaagaggtgggaacag & $60^{\circ} \mathrm{C}$ \\
14 & tcacatcttacaaactcaacaaaaa & ccaggagggttgcttaggta & $59^{\circ} \mathrm{C}$ \\
15 & ccagtctggcctcgagaact & tcacaaatattggccaggtg & $59^{\circ} \mathrm{C}$ \\
16 & ccagtcctgtaggtgctaaa & cttagccctgaaggaaaaat & $56^{\circ} \mathrm{C}$ \\
17 & tctaaatcactagcatttcctg & gaaagcattccgtaagatgt & $58^{\circ} \mathrm{C}$ \\
18 & tgggttcagaagttcttctcacta & ccccataccctccttgctac & $62^{\circ} \mathrm{C}$ \\
19 & gccagagcaggaagagtc & cgttgccactttgtttatc & $56^{\circ} \mathrm{C}$ \\
20 & gctactcactaaatgttcagctcct & cttgttcccccaggtgact & $62^{\circ} \mathrm{C}$ \\
21 & ctccaccggacttttggtaa & ggtgctcttctgttgccatt & $57^{\circ} \mathrm{C}$ \\
22 & gaattgacccctcaaggaca & aggcagaggtttcagtgagc & $61^{\circ} \mathrm{C}$ \\
23 & ggcagagttttgctcttgtca & tggtgaaaccccgtctctac & $58^{\circ} \mathrm{C}$ \\
24 & agtgcaggggcaggatct & gcatggggacagaggaataa & $58^{\circ} \mathrm{C}$ \\
25 & ccttttctcttcattttcccatt & ggatgagaggaaggaaagattc & $59^{\circ} \mathrm{C}$ \\
26 & tgcctgctttagaatgttttcc & agacaggtgcgtggataagg & $59^{\circ} \mathrm{C}$ \\
27 & aagttttcataagcacacttctaacc & tctctccagacaccagaagg & $61^{\circ} \mathrm{C}$ \\
& & & \\
\hline & & &
\end{tabular}

genetically redundant markers, the $r 2$ values showed relatively low values with an average of 0.13 between contiguous marker pairs (Figure 1).

We then assessed disease association of the 41 variants of interest, including these 40 SNPs of interest and the MOG51 microsatellite, in a sample set of 239 families using the extended transmission disequilibrium test (ETDT). Without taking linkage disequilibrium with variation at the HLA-DRB1-DQB1 loci into account, 11 SNPs -SNP07 (novel), SNP06 (novel), SNP05 (novel), rs2071652, rs2857767, SNP04 (novel), rs2535260, rs2535261, SNP03 (novel), rs2252734, rs29228 and the MOG51 microsatellite showed evidence of association at a significance level of $5 \%$ with MS (data not shown). We then evaluated MS association of these markers in an additional $158 \mathrm{MS}$ families (total $\mathrm{n}=397$ families). In this larger sample set, 8 markers showed some evidence of association at $5 \%$ significance level (Figure 2) with one haplotype defined by variants at rs2071652 (allele C), rs2857767 (allele C) and rs2535260 (allele C) showing the strongest disease association $\left(P=3.29 \times 10^{-6}\right)$. This level of significance was slightly lower than that shown by association of HLA-DRB1 $\left(P=7.9 \times 10^{-7}\right)$ and -DQB1 in the same sample set $\left(P=1.3 \times 10^{-7}\right)$. The transmission data of these variants individually and in the context of the three locus DRB1-DQB1-MOG haplotypes are shown in the online appendix along with the $D^{\prime}$ values among $M O G$ variants and the various DRB1-DQB1 haplotypes. The eight disease associated variants are essentially part of two main LD blocks formed, on the one hand by rs2071652, rs2857767 and rs2535260 and on the other hand by the other five variants. From these data it is evident that while SNP07, SNP06; SNP04, SNP03 are in positive LD only with the DRB1*0301-DQB1*0201 haplotype, SNPs rs2071652, rs2857767 and rs2535260 occur frequently (albeit at different degrees of positive LD from strong to modest) and show a significant association with more than one HLA-DRB1-DQB1 haplotype. The cooccurrence of these MOG variants with different DRB1DQB1 haplotypes could just be a chance event or could be due to any of the various forces which impact LD [37]. Importantly, we also assessed the disease association of MOG alleles which individually showed significant evidence of association with MS together with the other DRB1-DQB1 haplotypes grouped (that is, all DRB1-DQB1 haplotypes which did not show any evidence of significant association with MS). These extended DRB1-DQB1$M O G$ haplotypes showed a consistent negative transmission from parents to affected patients (see Additional file 1 ). This suggested that $M O G$ disease associations were most likely driven by $D R B 1-D Q B 1$ variation.

Next, we wanted to directly assess whether these MOG associations were independent from DRB1-DQB1 associations. To this end, we analysed the overall effect of allelic and haplotype variation at the MOG gene using the conditional ETDT (CETDT) [38]. Using this conditional analysis, which takes into account linkage disequilibrium between overall MOG variation and overall variation at the HLA-DQB1 and -DRB1 loci, MOG associations were no longer significant. Conversely, the overall associations of DRB1-DQB1 haplotypes, taking into account the most associated MOG haplotype, gave a $P$ value of $9.7 \times 10^{-3}$.

We also evaluated the relative transmission of the MOG alleles and haplotypes according to which specific DRB1$D Q A 1-D Q B 1$ haplotypes they were on (Figure 3). In order to carry out these analyses we used the haplotype method (HM)-TDT (Methods) [39]. Using this test we initially evaluated association of specific variants of $M O G$, taking into account linkage disequilibrium with the HLA-DRB1$D Q B 1$ haplotypes for which there is prior evidence of association with MS in the Sardinian population (i.e. DRB1*1303-DQB1*0301， DRB1*0405-DQB1*0301， DRB1*0301-DQB1*0201, DRB1*1501-DQB1*0602 and DRB $1 * 0405-\mathrm{DQB} 1 * 0302$ haplotypes) [13]. Again, allelic variation at the MOG locus did not significantly affect the transmission of these predisposing DRB1-DQB1 haplotypes (Figure 3). Also the MOG haplotype defined by rs2071652, rs2857767 and rs2535260 did not produce 


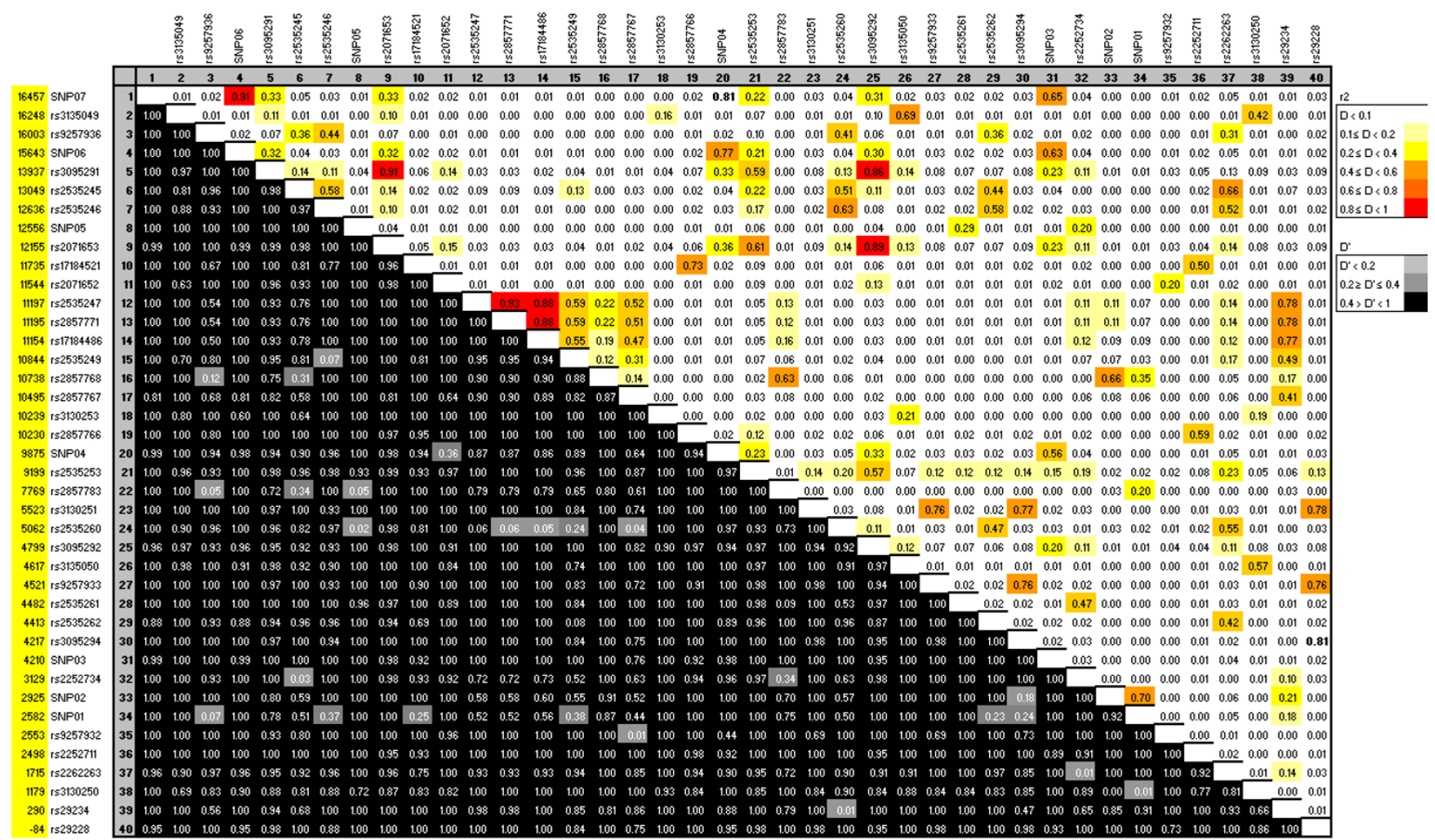

Figure I

Distribution of $r 2$ and $D^{\prime}$ intermarker values (above and below the diagonal respectively) for 40 SNPs analysed in 478 parents of Sardinian MS patients.

significant evidence of primary association when analysed with the HM-TDT conditional on DRB1-DQB1 positively associated haplotypes (data not shown). Moreover, we also conducted the HM-TDT to assess whether these MOG variants were influencing association of the non-predisposing DRB1-DQB1 haplotypes grouped. No significant heterogeneity in the association of DRB1-DQB1 haplotype conditional on MOG was seen, again suggesting that the initial observations of association with MS risk were likely to be only a consequence of LD with the DR-DQ mediated MS risk. This is shown in Figure 3, Graph F.

Considering our results globally, they provide evidence that haplotypes identical at the DRB1-DQB1 loci but different at the MOG locus do not have different associations with MS. Thus the significant association of MOG alleles and haplotypes appear to be secondary to hitchhiking effects due to variation at the DRB1-DQB1 loci. In interpreting these results it should be considered that the HLA region as a whole confers only a relatively modest contribution to the familial clustering and to the individual inherited risk of MS. Thus, the statistical power required to rule out a rare disease variant not detected in our resequencing, or even more dramatically, one that only slightly modulates the disease risk conferred by HLA$D R B 1-D Q B 1$ variants would require unrealistic sample sizes which exceed those used in this study. Still, our results and conclusions are consistent with those obtained in other populations [40], although there is still the suggestion that other non-DR-DQ genes may convey an independent risk to MS $[41,42,12,24]$.

The genetic results presented here have relevant mechanistic biological implications because they suggest that the protein product of the candidate gene MOG is unlikely to represent the primary autoantigen in human MS and thus cannot explain the target organ specificity observed in this disease. Contrast these data with the primary and consistent association detected with variation in the insulin gene (INS) region in type 1 diabetes and the epistatic deviations from a multiplicative model detected in the joint analysis of HLA class II and INS [43].

\section{Conclusion}

From our results we can conclude that variation at the MOG gene does not provide a significant independent contribution to the inherited risk for MS in the Sardinian population. The data suggests that the protein product of 


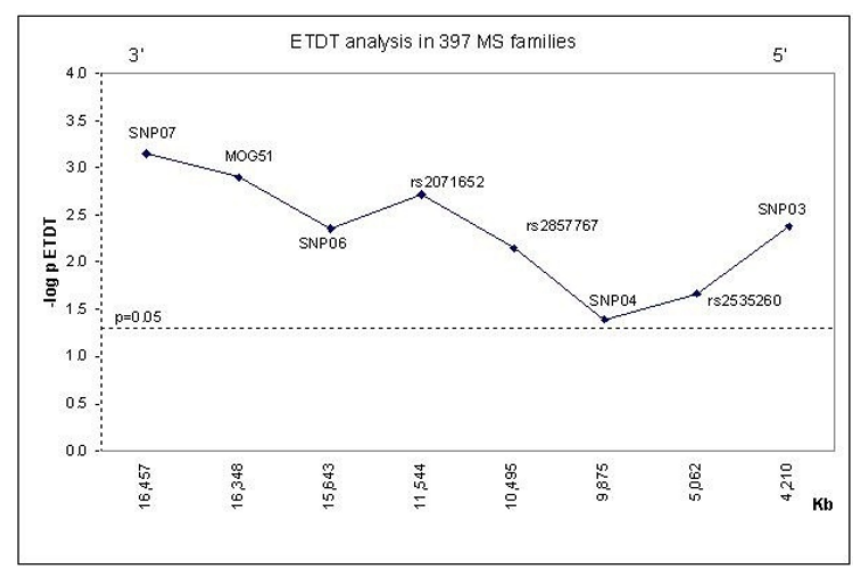

Figure 2

ETDT analysis in 397 MS families. Single-point association of I microsatellite and 8 SNP markers with MS within the MOG gene. Distances are given in $\mathrm{Kb}$ proceeding from the most centromeric marker, SNP07, to the most telomeric, SNP03. Association is presented as the negative log of the $P$-value for the extended transmission disequilibrium test (ETDT). The bold horizontal line corresponds to the threshold significance of 0.05

MOG is unlikely to represent the primary autoantigen in human MS.

\section{Methods}

\section{Study participants}

In the study we considered a sample set of 397 independent MS families, which included 391 trios families (one affected child and both healthy parents), 4 multiplex families (more than one affected sibling and their healthy parents) and 2 vertical families (one parent and one affected offspring), all being at least third generation Sardinian. This data set of 397 MS families is a proper subset of the 490 Sardinian MS families described previously [13]. All patients met the criteria of definite MS [33]. The average age of onset for MS was 28.9 years (range 6 - 51 years), and the female/male ratio was 2.3. The disease course was relapsing-remitting in $65 \%$, secondary progressive in $27 \%$ and primary progressive in $8 \%$ of patients. All families had previously been analysed at the DRB1-DQA1-DQB1 loci [13].

\section{Power calculations}

To examine the feasibility of verifying whether variants in the MOG gene, or in strong LD with it could explain the association peak that was previously observed in Sardinia [13], we focused on the parent-affected child trios that we had already studied during the initial examination of the role of the HLA in MS susceptibility. We postulated that our search would be for a fairly common variant (in line with the frequency of the predisposing DRB1-DQB1 hap- lotypes) with a maximal relative risk of 1.9 and using a disease prevalence of 0.0014 (corresponding to the prevalence in Sardinia). The strength of LD between the DRB1$D Q B 1$ locus and MOG was estimated at a mean value of $r^{2}=0.3$ as previously shown [13]. Purcell and Sham power calculations for our 391 trios gave for an alpha value of 0.10 a power of 0.83 [44]. It should be noted that for the conditional analyses, in the case of conditioning on the absence of high-risk HLA haplotypes, the trio size is 121 and the corresponding power is reduced to 0.42 for the same alpha criteria.

\section{MOG polymorphism analysis}

We resequenced the MOG gene in 21 parents of MS patients heterozygous for the 226 bp allele at the MOG51 microsatellite locus, which was found to be significantly associated with MS [13]. This selection of informative parents increases the chance of detecting relevant polymorphisms. 37 overlapping fragments covering the whole gene ( 8 exons and 7 introns) and -384 and 545 bp 5 ' and $3^{\prime}$ from the transcriptional unit were amplified and capillary sequenced (Megabace 1000). Overall, 16,561 bp were sequenced. Primers were designed according to the published human genomic DNA sequence [34] and are listed in Table 1). PCR was carried out in a final volume of $25 \mu \mathrm{l}$ using a specific combination of primers and $5 \mu \mathrm{l}$ of $4 \mathrm{ng} /$ $\mu \mathrm{l}$ genomic DNA. After an initial denaturation of 4 minutes at $95^{\circ} \mathrm{C}$, there were 37 cycles at $95^{\circ} \mathrm{C}$ for 30 seconds, at the specific TM primer for $30 \mathrm{~s}, 72^{\circ} \mathrm{C}$ for $30 \mathrm{~s}$ and a final extension at $72^{\circ} \mathrm{C}$ for 7 minutes.

A set of 40 informative SNPs was selected and dot-blot genotyped in the family sample set, using the set of primers listed in Table 1 and the SSO probes reported in Table 2. Selection of these SNPs was based on the patterns of LD (in order to provide good map coverage and avoid genotyping and testing genetically redundant variants), on the position in the gene (in order to maximise the chance of testing functionally relevant variants) and on the minor allele frequency (MAF) (in order to exclude particularly rare variants for which we did not have sufficient statistical power in the subsequent association stage).

In addition to these SNPs, in this manuscript we also assessed the association of MS with 1 intragenic microsatellite, MOG51 [34], whose primer sequences have been previously reported [13].

\section{Statistical analysis}

Single-point disease association of individual MOG variants as well as HLA-DRB1, DQB1 alleles was evaluated using ETDT [45]. This test takes into account the transmission or non-transmission of alleles of a locus relative to those present on the other parental chromosome. In the case of multiallelic markers, the ETDT takes multiple alle- 

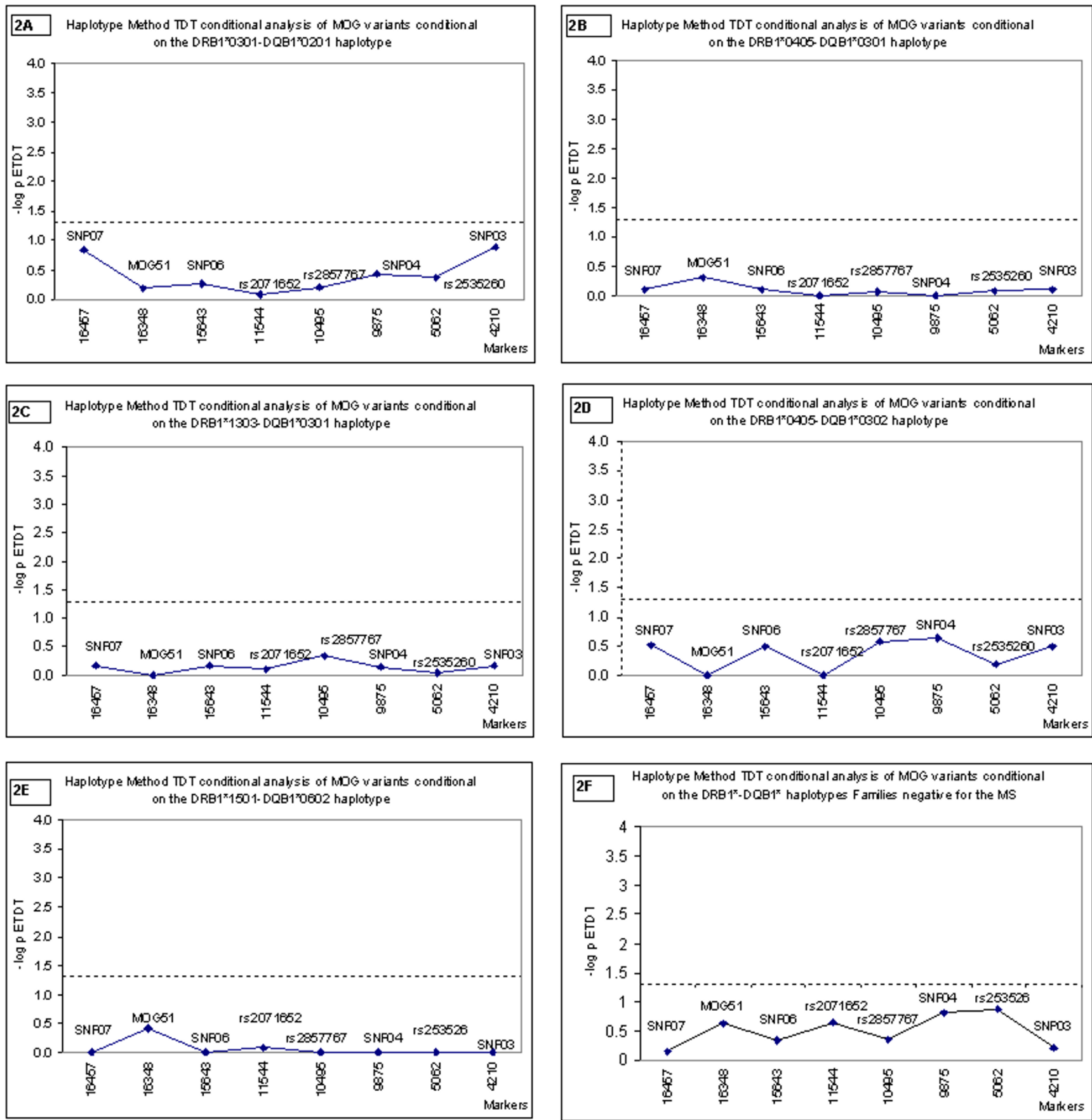

\section{Figure 3}

Association analysis of 8 MOG variants with MS conditional on DRB I-DQBI haplotypes using the Haplotype Method TDT Association analysis of 8 MOG variants with MS conditional on DRB I-DQBI haplotypes using the Haplotype Method-Transmission Disequilibrium Test HM-TDT [39]. The 8 MOG variants are the same shown in Figure I while the 5 predisposing DRBI-DQBI haplotypes refer to DRBI*030I-DQBI*020I (2A), DRBI*0405-DQBI*030 I (2B), DRBI*I303-DQBI*030I(2C), DRBI*0405DQBI*0302 (2D) and DRBI*I50I-DQBI*0602 (2E), with DRBI*-DQBI* families negative for MS haplotypes that showed prior evidence of association with MS (2F) [13]. Association is presented as the negative log of the $P$-value for the extended transmission disequilibrium test (ETDT). The bold horizontal line corresponds to the threshold significance of 0.05 
Table 2:

\begin{tabular}{|c|c|c|c|c|c|c|c|c|c|}
\hline Position & MAF (\%) & SNPs N. & & & PCR (bp) & & T.A. & Primer set (from Table I) & SSO probe \\
\hline-84 & 9.9 & I & rs29228 & $5^{\prime}$ & 613 & $\mathrm{~A} / \mathrm{G}$ & $57^{\circ} \mathrm{C}$ & 1 & cggacaaaaAcagaaatgt \\
\hline 290 & 5.6 & 2 & rs29234 & $5^{\prime}$ & 525 & $\mathrm{~A} / \mathrm{C}$ & $58^{\circ} \mathrm{C}$ & 2 & agctgagccAagaggtgag \\
\hline 1179 & 6.0 & 3 & $\mathrm{rs} 3130250$ & ExI & 762 & $\mathrm{G} / \mathrm{A}$ & $60^{\circ} \mathrm{C}$ & 3 & agcttatcGagaccctct \\
\hline 1715 & 23.0 & 4 & rs2262263 & IntrI & 509 & $\mathrm{~A} / \mathrm{G}$ & $60^{\circ} \mathrm{C}$ & 4 & $\operatorname{cccgcctcAgcttcccaa}$ \\
\hline 2498 & 7.3 & 5 & rs22527II & IntrI & 508 & $\mathrm{~T} / \mathrm{C}$ & $58^{\circ} \mathrm{C}$ & 5 & gagagacag Ttaaagtaga \\
\hline 2553 & 4.2 & 6 & rs9257932 & IntrI & 408 & $\mathrm{~T} / \mathrm{C}$ & $57^{\circ} \mathrm{C}$ & 6 & ggcagcaatTtggccaagt \\
\hline 2582 & 1.6 & 7 & SNPOI (novel) & IntrI & 408 & $\mathrm{G} / \mathrm{A}$ & $57^{\circ} \mathrm{C}$ & 6 & aggcccataGgaggattca \\
\hline 2925 & 1.7 & 8 & SNP02(novel) & Intrl & 706 & $\mathrm{~A} / \mathrm{G}$ & $59^{\circ} \mathrm{C}$ & 7 & attagctggAtgcggcggt \\
\hline 3129 & 22.8 & 9 & rs2252734 & IntrI & 568 & $\mathrm{C} / \mathrm{G}$ & $57^{\circ} \mathrm{C}$ & 8 & gaagaaCaattgcaatc \\
\hline 4210 & 12.6 & 10 & SNP03(novel) & Intr2 & 642 & $G / A$ & $58^{\circ} \mathrm{C}$ & 9 & gcccagcgecgtGgctc \\
\hline 4217 & 10.5 & 11 & rs3095294 & Intr2 & 642 & $\mathrm{~A} / \mathrm{G}$ & $58^{\circ} \mathrm{C}$ & 9 & ctcacAcctgtaatccca \\
\hline 4413 & 14.5 & 12 & rs 2535262 & Intr2 & 507 & $\mathrm{G} / \mathrm{A}$ & $57^{\circ} \mathrm{C}$ & 10 & gtgaacccGgaagcggag \\
\hline 4482 & 17.7 & 13 & rs2535261 & Intr2 & 507 & $\mathrm{G} / \mathrm{A}$ & $57^{\circ} \mathrm{C}$ & 10 & cagcgagactccGtctca \\
\hline 4521 & 9.8 & 14 & rs9257933 & Intr2 & 507 & $\mathrm{G} / \mathrm{A}$ & $57^{\circ} \mathrm{C}$ & 10 & gtatttgtgagcgcGcac \\
\hline 4617 & 7.0 & 15 & rs3135050 & Intr2 & 580 & $\mathrm{~T} / \mathrm{C}$ & $63^{\circ} \mathrm{C}$ & 11 & gagatgtcacTttttggc \\
\hline 4799 & 35.9 & 16 & rs3095292 & Intr2 & 580 & $\mathrm{G} / \mathrm{A}$ & $63^{\circ} \mathrm{C}$ & 11 & ccgagtagctgGgattac \\
\hline 5062 & 20.9 & 17 & rs 2535260 & Intr2 & 584 & $\mathrm{C} / \mathrm{G}$ & $62^{\circ} \mathrm{C}$ & 12 & aggtgaagcCgatggagg \\
\hline 5523 & 10.6 & 18 & rs 3130251 & Intr2 & 518 & $\mathrm{C} / \mathrm{T}$ & $60^{\circ} \mathrm{C}$ & 13 & cacctataaCcccaaaac \\
\hline 7769 & 1.1 & 19 & rs2857783 & Intr2 & 569 & $\mathrm{~T} / \mathrm{C}$ & $59^{\circ} \mathrm{C}$ & 14 & acttgaaagTaaaggtag \\
\hline 9199 & 47.4 & 20 & rs 2535253 & Intr2 & 591 & $\mathrm{~A} / \mathrm{C}$ & $59^{\circ} \mathrm{C}$ & 15 & attacaggaAtgtgccacc \\
\hline 9875 & 16.3 & 21 & SNP04(novel) & Intr2 & 404 & $\mathrm{~A} / \mathrm{G}$ & $56^{\circ} \mathrm{C}$ & 16 & ccttgagggActtcagat \\
\hline 10230 & 10.3 & 22 & rs2857766 & Ex3 & 493 & $\mathrm{G} / \mathrm{C}$ & $58^{\circ} \mathrm{C}$ & 17 & tcctgcagatcactGttg \\
\hline 10239 & 1.1 & 23 & rs3130253 & Ex3 & 493 & $\mathrm{G} / \mathrm{A}$ & $58^{\circ} \mathrm{C}$ & 17 & $\operatorname{ttggcctcGtcttcctct}$ \\
\hline 10495 & 4.4 & 24 & rs2857767 & Intr3 & 573 & $\mathrm{C} / \mathrm{G}$ & $62^{\circ} \mathrm{C}$ & 18 & taactatgCcatatagtaa \\
\hline 10738 & 1.3 & 25 & rs2857768 & Intr3 & 573 & $\mathrm{~T} / \mathrm{C}$ & $62^{\circ} \mathrm{C}$ & 18 & ttgtttcctcTttctccat \\
\hline 10844 & 6.7 & 26 & $\underline{\operatorname{rs} 2535249}$ & Intr3 & 573 & $\mathrm{~A} / \mathrm{G}$ & $62^{\circ} \mathrm{C}$ & 18 & tctccccaAtgccagagca \\
\hline 11154 & 4.5 & 27 & rs 17184486 & Intr3 & 493 & $\mathrm{~A} / \mathrm{G}$ & $56^{\circ} \mathrm{C}$ & 19 & gattctccAagcttcagtt \\
\hline 11195 & 5.3 & 28 & $\underline{\text { rs2857771 }}$ & Intr3 & 493 & $\mathrm{C} / \mathrm{T}$ & $56^{\circ} \mathrm{C}$ & 19 & aacatcctCcctcctaaat \\
\hline 11197 & 5.3 & 29 & rs 2535247 & Intr3 & 493 & $\mathrm{C} / \mathrm{G}$ & $56^{\circ} \mathrm{C}$ & 19 & aacatcctccCtcctaaat \\
\hline 11544 & 12.9 & 30 & rs 2071652 & Intr3 & 740 & $\mathrm{C} / \mathrm{T}$ & $62^{\circ} \mathrm{C}$ & 20 & ccaggctgCagagaaatag \\
\hline 11735 & 11.6 & 31 & $\underline{\mathrm{rs} 17184521}$ & Intr4 & 740 & $\mathrm{G} / \mathrm{A}$ & $62^{\circ} \mathrm{C}$ & 20 & aaatggtcccGttcttgga \\
\hline 12155 & 36.3 & 32 & rs2071653 & $\ln t r 5$ & 583 & $\mathrm{C} / \mathrm{T}$ & $57^{\circ} \mathrm{C}$ & 21 & tacaaaaaCgttatcttat \\
\hline 12556 & 9.2 & 33 & SNP05(novel) & Intr5 & 614 & $\mathrm{C} / \mathrm{A}$ & $61^{\circ} \mathrm{C}$ & 22 & cagatggtaCcttctctga \\
\hline 12636 & 17.6 & 34 & rs 2535246 & $\ln t r 5$ & 614 & $\mathrm{~T} / \mathrm{G}$ & $61^{\circ} \mathrm{C}$ & 22 & cacagagTtctatcgtacg \\
\hline 13049 & 22.2 & 35 & rs2535245 & Intr5 & 545 & $\mathrm{~T} / \mathrm{C}$ & $58^{\circ} \mathrm{C}$ & 23 & ctcagcctccTgagtagct \\
\hline 13937 & 35.8 & 36 & rs3095291 & Intr5 & 713 & $\mathrm{G} / \mathrm{C}$ & $58^{\circ} \mathrm{C}$ & 24 & cacgcccaGctaattttta \\
\hline 15643 & 13.9 & 37 & SNP06(novel) & Ex8 & 527 & $\mathrm{G} / \mathrm{A}$ & $59^{\circ} \mathrm{C}$ & 25 & tgtgaaggGaaggaagagg \\
\hline 16003 & 11.8 & 38 & $\underline{\text { rs9257936 }}$ & Ex8 & 593 & $\mathrm{C} / \mathrm{T}$ & $59^{\circ} \mathrm{C}$ & 26 & gataCgagttttggccggg \\
\hline 16248 & 6.2 & 39 & $\mathrm{rs} 3135049$ & Ex8 & 593 & $\mathrm{C} / \mathrm{T}$ & $59^{\circ} \mathrm{C}$ & 26 & agctgagatcgCgccactg \\
\hline 16457 & 13.8 & 40 & SNP07(novel) & $3^{\prime}$ & 569 & $\mathrm{~A} / \mathrm{G}$ & $61^{\circ} \mathrm{C}$ & 27 & attaccccagAggtcagtc \\
\hline
\end{tabular}


les into account and obtains a global $P$ value indicative of the degree of significance of the association with the disease at each individual locus. In order to distinguish primary associations from those due to linkage disequilibrium at the various assessed loci, we used a variant of the ETDT, called CETDT [38]. This test allows us to analyse the overall effect of one locus, in our case MOG, taking the overall association of variation at other loci into account; in this study DRB1 and DQB1. In order to study the transmission of specific $M O G$ alleles, conditioned on alleles or haplotypes at the DRB1-DQB1 disease loci, we used a TDT variant of the haplotype method [46]; the HM-TDT [39]. This method tests the null hypothesis of equality of transmission of haplotypes identical at one variant or combination of variants, but different at another closely-linked test locus [39]. If there is heterogeneity in the transmission of two marker haplotypes identical at a predisposing marker (variant A) but different at a putative predisposing marker at another site (variant $\mathrm{B}$ ), then this is evidence that variant A does not entirely explain disease predisposition and that variant $\mathrm{B}$ itself, or another marker in linkage disequilibrium with variant $B$, is influencing the transmission of variant $\mathrm{A}$ and, thus, disease susceptibility [39].

LD between individual SNPs at the MOG gene was assessed computing the $D^{\prime}$ and $r 2$ values. Both measures are built on the basic pairwise-disequilibrium coefficient, $D$, described by Lewontin [47], representing the difference between the probability of observing two marker alleles on the same haplotype and observing them independently in the population. The $D$ and normalised disequilibrium $D^{\prime}$, or $|D / D \max |$, values were computed on parental haplotypes using the software package [48]. A value of $D^{\prime}$ equal to 0.0 implies complete independence, whereas 1.0 implies that all copies of the rare allele occur exclusively with one of the two possible alleles at the other assessed marker. $R 2$, computed using a programme written by Jason Cooper, assesses not only LD between two markers but also the degree of matching between all allelic frequencies of both SNPs [49], thus encompassing the effects of both $D$ and all marker allele frequencies. As for $D^{\prime}$, an $r 2$ value of 0.0 also implies independence, but $r 2=1.0$ occurs only when the marker loci have identical allele frequencies and every occurrence of an allele at each of the markers perfectly predicts the allele at the other locus (i.e. in the presence of genetically indistinguishable makers). The two LD measures have different features: $D^{\prime}$ levels are useful to define the extent of $\mathrm{LD}$, for instance to establish the presence of the so-called LD blocks along chromosome intervals. Instead, $r 2$ are useful to establish marker informativity and the degree of genetic redundancy between selected SNPs and thus determine map coverage [49].

For all analyses performed in this manuscript, haplotypes were established following the co-segregation of alleles within families and using computer programmes written by F. Dudbridge and B. Koeleman. Only haplotypes showing definitive parental genotype data are considered in the analyses shown in this paper. In those families with more than one affected patient, only the probands were evaluated.

\section{Abbreviations \\ CETDT: conditional ETDT}

ETDT: extended transmission disequilibrium test

HM-TDT: haplotype method transmission disequilibrium test

LD: linkage disequilibrium

MOG: Myelin Oligodendrocyte Glycoprotein

MS: Multiple sclerosis

\section{Competing interests}

The author(s) declare that they have no competing interests.

\section{Authors' contributions}

MGM $^{1}$ participated in the study design, discussed results with $\mathbf{F C}^{3}$ and reviewed the manuscript. $\mathbf{R M}^{1}$ checked all data files for genotyping problems, performed statistical analysis on the data and designed all figures and tables. GC $^{1}$ set up and supervised the different protocols and methods performed.MCM ${ }^{1}, \mathbf{M R}^{1}, \mathbf{L S}^{1}$ and $\mathbf{E S}^{1}$ performed amplification and re-sequencing of all exons and introns. $S^{1}{ }^{1}$ completed all DNA extraction from peripheral blood. MAS $^{1}$ optimised DNA concentration for all samples and prepared all aliquots and dilutions. $\mathbf{E C}^{\mathbf{1}}$ organised family selection and maintained contacts with them for sample collection. MBW ${ }^{3}$ assisted in manuscript revision and statistical analysis. $\mathbf{M} \mathbf{P}^{2}, \mathbf{S S}^{2}$ and $\mathbf{G R}^{2}$ provided useful suggestions and collected DNA for part of the patients studied together with the related clinical data. $\mathrm{FC}^{3}$ supervised the study, analysed the results and wrote the manuscript. All authors read and approved the final manuscript.

\section{Additional material}

\section{Additional file 1}

TDT results for Alleles of the MOG haplotypes treated separately or with DRB1-DQB1. Transmission test for linkage disequilibrium was conducted with each of the alleles for the MOG haplotypes. The column on the left shows the results for each allele singly, while the column on the right shows the transmission results for HLA DRB1-DQB1 when the MOG allele is fixed.

Click here for file

[http://www.biomedcentral.com/content/supplementary/14712156-8-25-S1.doc] 


\section{Acknowledgements}

We wish to thank Rebecca Lewis for editorial assistance in the preparation of the manuscript and Jason Cooper for providing us with a programme to compute $r 2$ square values. This work was supported by FISM - Fondazione Italiana Sclerosi Multipla - Cod. 2004/R/5.

\section{References}

I. Withaker JM G.: Clinical feature of multiple sclerosis. In Multiple Sclerosis: Clinical and Pathogenetic Basis Edited by: In Raine CMFHTW. London; 1997:3-19.

2. Granieri E, Casetta I, Govoni V, Tola MR, Marchi D, Murgia SB, Ticca A, Pugliatti M, Murgia B, Rosati G: The increasing incidence and prevalence of $M S$ in a Sardinian province. Neurology 2000, 55(6):842-848.

3. Pugliatti M, Riise T, Sotgiu MA, Sotgiu S, Satta WM, Mannu L, Sanna G, Rosati G: Increasing incidence of multiple sclerosis in the province of Sassari, northern Sardinia. Neuroepidemiology 2005, 25(3): I29-134.

4. Pugliatti M, Sotgiu S, Solinas G, Castiglia P, Pirastru MI, Murgia B, Mannu L, Sanna G, Rosati G: Multiple sclerosis epidemiology in Sardinia: evidence for a true increasing risk. Acta Neurol Scand 200I, I 03(I):20-26

5. Ebers GC, Sadovnick AD, Risch NJ: A genetic basis for familial aggregation in multiple sclerosis. Canadian Collaborative Study Group. Nature |995, 377(6545):|50-|5|.

6. Compston A, Coles A: Multiple sclerosis. Lancet 2002, 359(93|3): $|22|-|23|$.

7. Barcellos LF, Oksenberg JR, Begovich AB, Martin ER, Schmidt S, Vittinghoff E, Goodin DS, Pelletier D, Lincoln RR, Bucher P, Swerdlin A, Pericak-Vance MA, Haines JL, Hauser SL: HLA-DR2 dose effect on susceptibility to multiple sclerosis and influence on disease course. Am J Hum Genet 2003, 72(3):710-716.

8. Stewart G], Teutsch SM, Castle M, Heard RN, Bennetts BH: HLADR, -DQAI and -DQBI associations in Australian multiple sclerosis patients. Eur J Immunogenet I997, 24(2):8I-92.

9. Laaksonen M, Pastinen T, Sjoroos M, Kuokkanen S, Ruutiainen J, Sumelahti ML, Reijonen H, Salonen R, Wikstrom J, Panelius M, Partanen J, Tienari PJ, Ilonen J: HLA class II associated risk and protection against multiple sclerosis-a Finnish family study. J

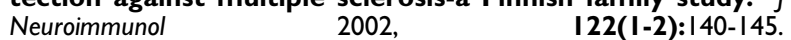

10. Chataway J, Feakes R, Coraddu F, Gray J, Deans J, Fraser M, Robertson N, Broadley S, Jones H, Clayton D, Goodfellow P, Sawcer S, Compston A: The genetics of multiple sclerosis: principles, background and updated results of the United Kingdom systematic genome screen. Brain 1998, I 2 I ( Pt I0): |869-I887.

I I. Oksenberg JR, Barcellos LF, Cree BA, Baranzini SE, Bugawan TL, Khan $O$, Lincoln RR, Swerdlin A, Mignot E, Lin L, Goodin D, Erlich HA, Schmidt S, Thomson G, Reich DE, Pericak-Vance MA, Haines JL, Hauser SL: Mapping multiple sclerosis susceptibility to the HLA-DR locus in African Americans. Am J Hum Genet 2004, 74(I): $160-167$.

12. Lincoln MR, Montpetit A, Cader MZ, Saarela J, Dyment DA, Tiislar M, Ferretti V, Tienari PJ, Sadovnick AD, Peltonen L, Ebers GC, Hudson $\mathrm{TJ}$ : A predominant role for the HLA class II region in the association of the $\mathrm{MHC}$ region with multiple sclerosis. Nat Genet 2005, 37(1 0): I I08-III2.

13. Marrosu MG, Murru R, Murru MR, Costa G, Zavattari P, Whalen M, Cocco E, Mancosu C, Schirru L, Solla E, Fadda E, Melis C, Porru I, Rolesu M, Cucca F: Dissection of the HLA association with multiple sclerosis in the founder isolated population of Sardinia. Hum Mol Genet 200I, I 0(25):2907-2916.

14. Masterman T, Ligers A, Olsson T, Andersson M, Olerup O, Hillert J: HLA-DRI 5 is associated with lower age at onset in multiple sclerosis. Ann Neurol 2000, 48(2):21 I-219.

15. C.Alvarado-de la Barrera, J. Zùniga-Ramos, J.A. Ruìz-Morales, B. Estanol, J. Granados, L. Llorente: HLA class II genotypes in Mexican Mestizos with familial and nonfamilial multiple sclerosis. Neurology 2000, 55:1897-1900.

16. Kwon OJ, Karni A, Israel S, Brautbar C, Amar A, Meiner Z, Abramsky $O$, Karussis D: HLA class II susceptibility to multiple sclerosis among Ashkenazi and non-Ashkenazi Jews. Arch Neurol 1999, 56(5):555-560.

17. Saruhan-Direskeneli G, Esin S, Baykan-Kurt B, Ornek I, Vaughan R, Eraksoy M: HLA-DR and -DQ associations with multiple sclerosis in Turkey. Hum Immunol I997, 55(I):59-65.
18. Luomala M, Elovaara I, Ukkonen M, Koivula T, Lehtimaki T: The combination of HLA-DRI and HLA-DR53 protects against MS. Neurology 200I, 56(3):383-385.

19. Coraddu F, Reyes-Yanez MP, Parra A, Gray J, Smith SI, Taylor C] Compston DA: HLA associations with multiple sclerosis in the Canary Islands. J Neuroimmunol | 998, 87( I-2): | 30- I 35.

20. Caballero A, Alves-Leon S, Papais-Alvarenga R, Fernandez O, Navarro $G$, Alonso A: DQB I*0602 confers genetic susceptibility to multiple sclerosis in Afro-Brazilians. Tissue Antigens 1999 , 54(5):524-526.

21. Fogdell-Hahn A, Ligers A, Gronning M, Hillert J, Olerup O: Multiple sclerosis: a modifying influence of HLA class I genes in an HLA class II associated autoimmune disease. Tissue Antigens 2000, 55(2): | $40-148$.

22. Ebers GC, Kukay K, Bulman DE, Sadovnick AD, Rice G, Anderson C Armstrong H, Cousin K, Bell RB, Hader W, Paty DW, Hashimoto S, Oger J, Duquette P, Warren S, Gray T, O'Connor P, Nath A, Auty A, Metz L, Francis G, Paulseth JE, Murray T], Pryse-Phillips W, Nelson R, Freedman M, Brunet D, Bouchard JP, Hinds D, Risch N: A full genome search in multiple sclerosis. Nat Genet 1996, I3(4):472-476.

23. Bitti PP, Murgia BS, Ticca A, Ferrai R, Musu L, Piras ML, Puledda E, Campo S, Durando S, Montomoli C, Clayton DG, Mander AP, Bernardinelli L: Association between the ancestral haplotype HLA A30B I 8DR3 and multiple sclerosis in central Sardinia. Genet Epidemiol 200I, 20(2):27I-283.

24. Rubio JP, Bahlo M, Stankovich J, Burfoot RK, Johnson LJ, Huxtable S, Butzkueven H, Lin L, Taylor BV, Speed TP, Kilpatrick TJ, Mignot E, Foote S): Analysis of extended HLA haplotypes in multiple sclerosis and narcolepsy families confirms a predisposing effect for the class I region in Tasmanian MS patients. Immunogenetics 2007, 59(3): I77-186.

25. Stefferl A, Brehm U, Storch M, Lambracht-Washington D, Bourquin C, Wonigeit K, Lassmann H, Linington C: Myelin oligodendrocyte glycoprotein induces experimental autoimmune encephalomyelitis in the "resistant" Brown Norway rat: disease susceptibility is determined by $\mathrm{MHC}$ and MHC-linked effects on the B cell response. J Immunol 1999, I 63(I):40-49.

26. Mendel I, Gur H, Kerlero de Rosbo N, Ben-Nun A: Experimental autoimmune encephalomyelitis induced in B6.C-H-2bm I 2 mice by myelin oligodendrocyte glycoprotein: effect of MHC class II mutation on immunodominant epitope selection and fine epitope specificity of encephalitogenic T cells. J Neuroimmunol 1999, 96(I):9-20.

27. Kerlero de Rosbo N, Hoffmann M, Mendel I, Yust I, Kaye J, Bakimer R, Flechter S, Abramsky O, Milo R, Karni A, A BN: Predominance of the autoimmune response to myelin oligodendrocyte glycoprotein (MOG) in multiple sclerosis: reactivity to the extracellular domain of MOG is directed against three main regions. Eur J Immunol 1997, 27:3059-3069.

28. Wallstrom E, Khademi M, Andersson M, Weissert R, Linington C, Olsson T: Increased reactivity to myelin oligodendrocyte glycoprotein peptides and epitope mapping in HLA DR2(I5)+ multiple sclerosis. Eur J Immunol 1998 28(I0):3329-3335.

29. Raine CS, Cannella B, Hauser SL, Genain CP: Demyelination in primate autoimmune encephalomyelitis and acute multiple sclerosis lesions: a case for antigen-specific antibody mediation. Ann Neurol 1999, 46(2): |44-160.

30. O'Connor. KC, McLaughlin KA, De Jager PL, Chitnis T, Bettelli E, Xu C, Robinson WH, Cherry SV, Bar-Or A, Banwell B, Fukaura H, Fukazawa T, Tenembaum S, Wong SJ, Tavakoli NP, Idrissova Z, Viglietta V, Rostasy K, Pohl D, Dale RC, Freedman M, Steinman L, Buckle G], Kuchroo VK, Hafler DA, Wucherpfennig KW: Self-antigen tetramers discriminate between myelin autoantibodies to native or denatured protein. Nat Med 2007, I3(2):2 I I-2 I7.

31. Kuhle J, Pohl C, Mehling M, Edan G, Freedman MS, Hartung HP, Polman CH, Miller DH, Montalban X, Barkhof F, Bauer L, Dahms S, Lindberg R, Kappos L, Sandbrink R: Lack of association between antimyelin antibodies and progression to multiple sclerosis. $N$ Engl J Med 2007, 356(4):37|-378.

32. Seboun E, Oksenberg JR, Rombos A, Usuku K, Goodkin DE, Lincoln RR, Wong M, Pham-Dinh D, Boesplug-Tanguy O, Carsique R, Fitoussi R, Gartioux C, Reyes C, Ribierre F, Faure S, Fizames C, Gyapay G, Weissenbach J, Dautigny A, Rimmler JB, Garcia ME, Pericak-Vance MA, Haines JL, Hauser SL: Linkage analysis of candidate myelin 
genes in familial multiple sclerosis. Neurogenetics 1999, 2(3): $155-162$.

33. Gomez-Lira M, Moretto G, Bonamini D, Benedetti MD, Pignatti PF, Rizzuto N, Salviati A: Myelin oligodendrocyte glycoprotein polymorphisms and multiple sclerosis. J Neuroimmunol 2002, I 33(I-2):24I-243.

34. Roth MP, Malfroy L, Offer C, Sevin J, Enault G, Borot N, Pontarotti P, Coppin $\mathrm{H}$ : The human myelin oligodendrocyte glycoprotein (MOG) gene: complete nucleotide sequence and structural characterization. Genomics 1995, 28(2):24I-250.

35. Ohlenbusch A, Pohl D, Hanefeld F: Myelin oligodendrocyte gene polymorphisms and childhood multiple sclerosis. Pediatr Res 2002, 52(2): $175-179$.

36. National Center for Biotechnology Information, http:// www.ncbi.nlm.nih.gov/: . .

37. Zavattari P, Deidda E, Whalen M, Lampis R, Mulargia A, Loddo M, Eaves I, Mastio G, Todd JA, Cucca F: Major factors influencing linkage disequilibrium by analysis of different chromosome regions in distinct populations: demography, chromosome recombination frequency and selection. Hum Mol Genet 2000, 9(20):2947-2957.

38. Koeleman BP, Dudbridge F, Cordell HJ, Todd JA: Adaptation of the extended transmission/disequilibrium test to distinguish disease associations of multiple loci: the Conditional Extended Transmission/Disequilibrium Test. Ann Hum Genet 2000, 64(Pt 3):207-213.

39. Cucca F, Dudbridge F, Loddo M, Mulargia AP, Lampis R, Angius E, De Virgiliis S, Koeleman BP, Bain SC, Barnett AH, Gilchrist F, Cordell H, Welsh K, Todd JA: The HLA-DPB I--associated component of the IDDMI and its relationship to the major loci HLA-DQB I, -DQAI, and -DRBI. Diabetes 200I, 50(5): I200-I205.

40. Rubio JP, Bahlo M, Tubridy N, Stankovich J, Burfoot R, Butzkueven $H$, Chapman C, Johnson L, Marriott M, Mraz G, Tait B, Wilkinson C, Taylor B, Speed TP, Foote S], Kilpatrick T]: Extended haplotype analysis in the HLA complex reveals an increased frequency of the HFE-C282Y mutation in individuals with multiple sclerosis. Hum Genet 2004, I I 4(6):573-580.

4I. Yeo TW, De Jager PL, Gregory SG, Barcellos LF, Walton A, Goris A, Fenoglio C, Ban M, Taylor CJ, Goodman RS, Walsh E, Wolfish CS, Horton R, Traherne J, Beck S, Trowsdale J, Caillier SJ, Ivinson AJ, Green T, Pobywajlo S, Lander ES, Pericak-Vance MA, Haines JL, Daly MJ, Oksenberg JR, Hauser SL, Compston A, Hafler DA, Rioux JD, Sawcer S: A second major histocompatibility complex susceptibility locus for multiple sclerosis. Ann Neurol 2007, 6I(3):228-236.

42. Rubio JP, Bahlo M, Butzkueven $H$, van Der Mei IA, Sale MM, Dickinson JL, Groom P, Johnson LJ, Simmons RD, Tait B, Varney M, Taylor B, Dwyer T, Williamson R, Gough NM, Kilpatrick TJ, Speed TP, Foote SJ: Genetic dissection of the human leukocyte antigen region by use of haplotypes of Tasmanians with multiple sclerosis. Am J Hum Genet 2002, 70(5): I I 25- I I 37.

43. Motzo C, Contu D, Cordell HJ, Lampis R, Congia M, Marrosu MG, Todd JA, Devoto M, Cucca F: Heterogeneity in the magnitude of the insulin gene effect on HLA risk in type I diabetes. Diabetes 2004, 53(1 2):3286-329I.

44. Purcell S, Cherny SS, Sham PC: Genetic Power Calculator: design of linkage and association genetic mapping studies of complex traits. Bioinformatics 2003, I9(I): $149-150$.

45. Sham PC, Curtis D: An extended transmission/disequilibrium test (TDT) for multi-allele marker loci. Ann Hum Genet 1995, 59 ( Pt 3):323-336.

46. Valdes AM, Thomson G: Detecting disease-predisposing variants: the haplotype method. Am J Hum Genet 1997, 60(3):703-7I6.

47. Lewontin RC: On measures of gametic disequilibrium. Genetics 1988, I 20(3):849-852.

48. A software for population genetics data analysis, http://lgb.unige.ch/ arlequin/: .

49. Zondervan KT, Cardon LR: The complex interplay among factors that influence allelic association. Nat Rev Genet 2004, 5(2):89-100.
Publish with Biomed Central and every scientist can read your work free of charge

"BioMed Central will be the most significant development for disseminating the results of biomedical research in our lifetime. "

Sir Paul Nurse, Cancer Research UK

Your research papers will be:

- available free of charge to the entire biomedical community

- peer reviewed and published immediately upon acceptance

- cited in PubMed and archived on PubMed Central

- yours - you keep the copyright

Submit your manuscript here:

http://www.biomedcentral.com/info/publishing_adv.asp
BioMedcentral 